\title{
La aportación de las Universidades Vascas al Cooperativismo. El Instituto de Estudios Cooperativos de la Universidad de Deusto
}

\author{
Marta Enciso Santocildes
}

Sumario: 1. Formación.-2. Investigación.-3. Biblioteca especializada.-4. Difusión.-5. El Instituto para los próximos años.

En memoria del P. Dionisio Aranzadi S. J., fundador de este Instituto, fallecido el 13 de julio de 2008. Con todo el respeto, gratitud y reconocimiento de una discípula a su maestro. Con el afecto a un amigo que si bien se ha ido permanecerá en mi recuerdo.

El Instituto de Estudios Cooperativos de la Universidad de Deusto se instituyó a principios de los años 80 y fue el primero de los institutos especializados en esta materia en la Comunidad Autónoma del País Vasco (CAPV). La línea de trabajo, investigación y docencia en materia de cooperativismo constituía uno de los puntos fuertes y reconocidos en nuestra universidad. Por un lado, en la Facultad de Sociología el Profesor Dionisio Aranzadi S. J., dirigía la Cátedra de Cooperativismo "Jose M. ${ }^{a}$ Arizmendiarrieta». Por su parte, en la de Derecho, el Profesor Javier Divar había ya incorporado a sus clases de Derecho Mercantil unas lecciones sobre sociedades cooperativas. Asimismo, dos profesores, Alejandro Martínez y Jose M. ${ }^{a}$ Merino comenzaban a mostrar su interés por los temas cooperativos.

La reflexión de la tradición e importancia del movimiento cooperativo en el País Vasco, la consideración sobre su papel, y la ausencia de otros centros universitarios de formación e investigación, aconsejaron la creación de este centro, con el carácter de un instituto superior multidisciplinar, que participa de la personalidad de la Universidad de Deusto y se rige por los Estatutos de la misma.

El contexto externo a la propia Universidad era asimismo propicio en relación al cooperativismo. Por un lado en pertenecer a una Comunidad Autónoma donde la presencia del cooperativismo y la Economía 
Social era fuerte, exitosa y consolidada. Sin lugar a dudas la Experiencia de Mondragón, de reconocimiento mundial constituye el mayor exponente, pero encontrábamos también un buen numero de entidades de menor dimensión presentes en toda la geografía vasca y en un buen número de sectores económicos.

Por otro lado, la Dirección de Economía Social adscrita al Departamento de Trabajo del Gobierno Vasco con el objetivo decidido de promoción del Cooperativismo y de la Economía Social, apoyó la constitución de este instituto con su impulso y financiación, que se mantienen hasta nuestros días.

Coincide en el tiempo con un buen número de iniciativas relacionadas con el cooperativismo, su fomento, apoyo y difusión. Así, por ejemplo, cabe mencionar la promulgación de la Ley Vasca de Cooperativas de 11 de febrero de $1982^{1}$, la primera a nivel español, en el marco de sus competencias exclusivas (art. 10-23 del Estatuto de Autonomía del País Vasco 2l) Asimismo, la presencia y actuación del Consejo Superior de Cooperativas de Euskadi, formalmente constituido el 28 de Enero de 1983. De esta misma década son la constitución como asociación de Ciriec España (1986) o ASLE , la Agrupación de Sociedades Laborales de Euskadi (1982). Vemos que desde el punto de vista de consolidación del movimiento y de sus entidades fue una década fructífera.

Fueron momentos en que el Cooperativismo y otras fórmulas de Economía Social, como las Sociedades Laborales, cobraron un protagonismo en el plano económico y social tanto a nivel vasco, como estatal y europeo.

Por un lado la crisis que azotó el País Vasco, junto al resto de las economías en los años 80. Así y todo la Economía Vasca tenía una serie de características especiales por ser una región industrializada centrada en sectores maduros, tradicionales, con limitada capacidad de adaptación a los cambios lo que produjo su configuración como una región en declive, con altas tasas de paro y abandono de espacios industriales. Se crearon un buen número de cooperativas y sociedades laborales en un intento de dar solución a los problemas económicos y de gestión de las empresas, tomando los trabajadores las riendas de los negocios en un intento de no cesar la actividad y mantener los puestos de trabajo. La necesidad e interés desde los poderes públicos de proteger a estas entidades era evidente.

Por otro lado, podemos mencionar la actividad a nivel de la entonces Comunidad Económica Europea (CEE) en relación al cooperativismo.

\footnotetext{
1 Ley 1/1982, de 11 de Febrero, sobre Cooperativas del País Vasco.

2 Ley Orgánica 3/1979, de 18 de diciembre, Estatuto de Autonomía del País Vasco.
} 
Efectivamente, se trata de un período de tiempo en que se presta atención al cooperativismo, llevándose a cabo iniciativas de diverso tipo tales como Conferencias de Economía Social, elaboración de estadísticas e investigaciones científicas, constitución de una unidad específica dentro del la Dirección General XXIII, los tres proyectos de Estatuto europeo o el establecimiento de ayudas y programas de trabajo plurianuales.

Todos estos movimientos se produjeron a instancia de las organizaciones cooperativas con sede en Bruselas y su labor como lobbies. Se centraron en intentar demostrar las especificidades y efectos positivos del cooperativismo y en general del tercer sector con el fin de ser reconocidos, evitar discriminaciones precisamente por la ausencia de diferención, y ser objeto de acciones de fomento y apoyo a nivel institucional en el marco de la CEE. ${ }^{3}$

Este es el contexto social, económico e institucional en que se enmarca la creación en la Universidad de Deusto de este Instituto especializado. La dirección del Instituto se encargó al P. Aranzadi, siendo Secretarios Académico y Técnico, Javier Divar y Alejandro Martínez respectivamente. En el año 1994 entró Aitziber Mugarra como Secretaria, siendo designada en 1999 como Directora, cargo que continúa ocupando en la actualidad.

En este momento podemos destacar las siguientes áreas de trabajo y de manera resumida su labor en los últimos años.

\section{Formación}

Las primeras tareas fueron fundamentalmente de tipo formativas a través de cursos y seminarios de especialización. Se ajustaba plenamente a las demandas del movimiento y de la exigencia de formación del quinto principio cooperativo. De la misma manera se justificaba por el interés en difundir la idea y la esencia cooperativa entre titulados superiores para una posible inclusión en el mercado laboral en estas entidades. Junto a esto, la investigación científica, las relaciones con el movimiento cooperativo vasco e internacional y la colaboración con diversas instituciones centraban la labor del instituto. El primer curso de especialización dio comienzo el curso 1984-85.

En materia de formación en la actualidad se ofrece un Postgrado en Gestión de Empresas Cooperativas, Sociales y Solidarias. Se trata de

\footnotetext{
${ }^{3}$ Ver al respecto, ENCISo SANTOCILDES, M (2002), La Regionalización de la Alianza Cooperativa Internacional. Análisis Específico de la Situación en Europa. UMI.
} 
un Master de especialización, de carácter oficial, con una duración de 60 créditos ECTS. Este programa viene a sustituir al Diploma de Especialización en cooperativismo que se ha venido impartiendo desde hace más de 20 años.

Asimismo, se organizan Seminarios y Conferencias especializados. De carácter básico e introductorio dirigido a dar a conocer el cooperativismo y la economía social entre futuros titulados superiores. En esta labor formativa y de difusión se organizan conferencias, algunas de ellas ligadas a otros hitos tales como el día europeo del emprendimiento o la semana vasca de la calidad Euskalit.

A estas acciones de formación general se unen otras a medida, a demanda de empresas, entidades y organizaciones tanto vascas como internacionales y estatales.

La formación se completa con la colaboración de miembros y colaboradores del Instituto en programas de otros centros de la Universidad de Deusto, de otros centros de la CAPV así como de otras Universidades nacionales e internacionales.

\section{Investigación}

Se trata de otro de los grandes ejes de actuación del Instituto. Para ello se participa en redes nacionales e internacionales y se procuran contratos y convenios tanto con entidades públicas como privadas. La manera de trabajar es en red, de manera que establemente hay un número limitado de investigadores y personal adscrito al instituto, solicitando colaboraciones a diferentes personas de dentro y fuera de la Universidad de Deusto para proyectos concretos. Asimismo, se ha obtenido la consideración por parte de la Universidad de Deusto de grupo y línea de investigación reconocida.

A nivel Internacional se ha participado entre otros en redes con Canadá y CIRIEC Internacional, a nivel de la Unión Europea Programa a través del programa Alfa-II y como grupo emergente dentro de Obreal Eurolauro. Las colaboraciones con otras universidades tales como la Universidad del País Vasco (UPV), Mondragón Unibertsitatea (MU) o la Universidad de Zaragoza y a nivel internacional Helsinki, Roma Tre, UNISINOS en Brasil, La Plata en Argentina o la Pontificia Universidad Javeriana de Bogotá, por citar algunas, son intensas.

Las relaciones con entidades e instituciones cooperativas, tales como ACl Américas, el Consejo de Superior de Cooperativas de Euskadi, la Dirección de Economía Social del Gobierno Vasco, las diferentes federaciones y diversas entidades cooperativas y de economía social en el desarrollo de temas de interés mutuo es constante. 


\section{Biblioteca especializada}

Desde el Instituto se ha realizado un importante esfuerzo en dotar a la Biblioteca General de la Universidad de un fondo especializado en Cooperativismo y Economía Social a través de adquisiciones, donaciones e intercambios de publicaciones. En este momento el fondo esta formado por unas 5.700 monografías accesibles a todos los investigadores, profesores y alumnos. Se puede acceder al catálogo a través de la página web de la Universidad (www.deusto.es) y su nuevo sistema amicus, que permite búsquedas y su tratamiento.

Con el fin de facilitar el trabajo investigador se ha organizado una base de datos y un thesauro, que estará a disposición pública en breve. Por el momento, pueden encontrarse listados alfabéticos de todas las monografías en la página web del instituto (www.coop.deusto.es)

La accesibilidad a la colección y la mejora de los servicios a usuarios e investigadores va a verse acrecentada con la inauguración en octubre de 2008 del CRAE (Centro de Recursos para el Aprendizaje y la Investigación), que se está construyendo en la otra orilla de la ría. Con ello se pondrán $27.000 \mathrm{~m} 2$ a disposición de todos en un magnífico edificio diseñado por el arquitecto Moneo.

En cuanto a la colección de revistas periódicas, la colección alcanza el nada despreciable número de 182 registros, procedentes de diferentes sectores y países.

\section{Difusión}

En su vertiente de investigación y difusión el Instituto publica desde 1984 un Anuario de Estudios Cooperativos en el que se recogen la memoria del curso anterior, las conferencias de clausura e inauguración del curso, así como colaboraciones de profesores e investigadores especializados en esta materia, tanto a nivel internacional como nacional.

En estos últimos años el esfuerzo editor del instituto se ha centrado en la publicación de tres libros que recogen los resultados investigadores, uno junto a la UPV y la MU y otros dos que verán la luz a finales de 2008 y principios de 2009 sobre responsabilidad social y desarrollo sostenible. Tras este paréntesis se volverá a editar esta publicación periódica.

Constituye otro importante objetivo presentar en otros anuarios y publicaciones científicas a nivel nacional e internacional artículos elaborados por miembros de instituto, así como participar en congresos científicos en el ámbito cooperativo y extracooperativo. 
Por último, en materia de difusión se lleva a cabo una revista de prensa desde el año 1996 en que se recogen todos los titulares aparecidos en la prensa general referidos a este sector en nuestra comunidad autónoma. Los objetivos son, por un lado, dar a conocer e informar sobre la realidad del movimiento cooperativo y de la Economía Social en el País Vasco, y por otro, servir de recordatorio sobre los acontecimientos más significativos que han tenido lugar a lo largo de cada año. Una selección de los titulares más relevantes está disponible en la web del instituto y serán actualizados en breve.

\section{El Instituto para los próximos años}

Nos acercamos casi al cuarto de siglo de existencia del Instituto y nos volvemos a plantear la mismas cuestiones que se plantearon los promotores y fundadores del mismo ¿tiene sentido un instituto especializado en materia cooperativa? ¿cuál es el papel que le corresponde desempeñar? A la primera pregunta, si tiene sentido hoy día, la respuesta rotundamente es afirmativa. Las especificidades cooperativas no han desaparecido más bien al contrario, se han puesto en valor, al igual que se mantiene la necesidad de formar a los jóvenes licenciados que salen al mercado laboral en "otro modo de hacer empresa», parafraseando a los clásicos.

La importancia de la educación y difusión cooperativa, denominada regla de oro del cooperativismo, tiene hoy si cabe mayor importancia. Pues como pone de manifiesto la propia Alianza Cooperativa Internacional $(\mathrm{ACl})$ en el documento de trabajo sobre los principios, la gente no aprecia ni apoya lo que no entiende» ${ }^{4}$.

En cuanto a la segunda pregunta, el papel que debe cumplir el Instituto, debemos responder que el mismo que se otorgó en su orígenes: formación, investigación y difusión, en un contexto de colaboración y estructura de red adaptado a los nuevos tiempos en que discurre hoy día su labor.

${ }^{4}$ Alianza CoOperativa Internacional, "Background paper on the ICA statement on the co-operative identity» en ACI-Alianza CoOperativa INTERnACIONAL (1995a): XXXI ICA Congress: Manchester 1995: agenda \& reports (Congreso, 31., 1995, Manchester). Genève: $\mathrm{ACl}$, pp. 26 y 27. 